\title{
Semantic processing and organization in free recall
}

\author{
FRANCIS S. BELLEZZA, DEBORAH L. RICHARDS, and RALPH E. GEISELMAN \\ Ohio University, Athens, Ohio 45701
}

\begin{abstract}
It was hypothesized that both semantic processing and organizational activity are necessary for optimal free recall performance. In a series of three experiments, subjects were presented with a list of randomly selected nouns and were asked to make up a meaningful sentence for each noun. The subjects also rated the difficulty of using each noun. The subjects were instructed to try to remember words that were labeled "remember" words. For words that were labeled "story" words, the subjects were instructed only to make each sentence, using the word, part of an ongoing story which each subject was to make up. A test of retention for all presented words, using retention intervals of both $1 \mathrm{~min}$ and $24 \mathrm{~h}$, showed that the story words were always recalled better than were the remember words. However, the amount of sequential organization was the same for both the story and the remember words. Recognition performance was found to be the same for both types of words. In addition, the story words were rated as being more difficult than the remember words. It was concluded that extensive semantic processing without organization is not sufficient for optimal recall.
\end{abstract}

With the weakening of the influence of stimulusresponse theory as an explanation of human learning, a number of new paradigms have been proposed, especially in the area of free recall learning. According to Mandler (1967), the memorization or retention of a set of unrelated words is the result of the material having been organized by the subject using such processes as seriation, categorization, and relational imagery (Mandler, 1970). In a series of experiments, Mandler (1967) showed that instructions to organize the words into groups had the same effect on the number of words recalled as did instructions to remember the words. Mandler has also suggested that, if the subject must create a large number of groups or categories in organizing the items, then these categories may themselves be organized into higher level categories. This results in an organizational hierarchy which allows the subject to efficiently search for any item when asked to recall (Mandler, 1968). Similar arguments have also been made by Tulving $(1962,1968)$.

From a somewhat different point of view, Craik and Lockhart (1972) have proposed a levels-of-processing explanation of remembering which argues that "the memory trace can be understood as a by-product of perceptual analysis and that trace persistence is a positive function of the depth to which the stimulus has been analyzed" (p. 671). Good recall is the result of individual words undergoing extensive processing

Requests for reprints should be sent to Francis S. Bellezza, Department of Psychology, Ohio University, Athens, Ohio 45701. This research was supported in part by a grant from the Field-Wiltsie Foundation. Portions of this research were presented at the annual meeting of the Midwestern Psychological Association, Chicago, May 1975. by enrichment or elaboration. Is it possible that degree of organization and depth of processing represent the same basic notion that is being expressed using different terminology? The two approaches seem to overlap. At some points in their discussion, Craik and Lockhart (1972) indicate that organization is the equivalent of deep and extensive processing, while, at other points, they indicate that levels of processing cannot yet explain how items are organized. In a subsequent article, Craik (1973) states that "we want to know to what extent memory is simply a function of depth of encoding and to what extent further notions like retrieval cues, accessibility, and interitem organization are necessary" (p. 61). The difference in emphasis between the notions of levels of processing and organization when discussing free recall is, perhaps, best brought out by utilizing Tulving's (1972) distinction between encoding and organization. Encoding a word transforms it independently of other presented words, but may relate the word to other known words in semantic memory. On the other hand, organization of a word is not independent of the other presented words and, in fact, may involve relating the word to other presented words.

In considering the relation between organization and processing, it seems that the organization of a list of to-be-remembered words cannot take place until the words have been processed to the extent that their meanings are comprehended (Jenkins, 1974). Organization of the items and, thus, recall of the items are dependent on the items first being semantically processed. This requirement has been demonstrated in a series of experiments by Jenkins and his associates (Hyde \& Jenkins, 1969; Till \& Jenkins, 1973; Walsh \& Jenkins, 1973). They found that, unless words were 
processed as meaningful units, recall was impaired and associative clustering did not take place. Whether or not the subjects knew that they would be asked to recall the words had little effect on the number of words recalled when compared to the effect of having to process the words semantically, as opposed to processing the words orthographically, syntactically, or phonetically (Walsh \& Jenkins, 1973). Because the amount of recall and the degree of associative clustering were equal in groups instructed only to semantically process the words, Hyde and Jenkins (1969) concluded that organization and recall are both the product of semantic processing. The purpose of the series of experiments presented here is to show that organization is not merely the by-product of semantic processing, but can be independently manipulated, even when a great deal of semantic processing has also taken place. The effect of this additional organization is to further increase the number of words recalled. Semantic processing is necessary for optimal recall, but it is not sufficient. Organization must also take place.

\section{EXPERIMENT I}

\section{Method}

Subjects. The subjects were 56 volunteers from introductory psychology courses at Ohio University who received course credit for their participation.

Materials and apparatus. Four randomized lists of nouns were generated, each consisting of a practice list of 6 words and a main list of 42 words. The words in each list were randomly sampled from the norms of Paivio, Yuille, and Madigan (1968), with the restriction that no word was more than eight letters long.

Procedure. The subjects were tested individually using a Lafayette IBM memory drum. Each subject was randomly assigned to a condition and a list when he arrived for the experiment. The subjects were told that the purpose of the experiment was to rate the difficulty of words which were being considered for use in grade school textbooks. Each word was presented for $11 \mathrm{sec}$ and each subject was instructed to give a sentence using the word in a meaningful way and then to verbally rate on a 5-point scale of difficulty the difficulty of using the word. A 1 indicated that the word was very easy to use and a 5 indicated that it was very difficult. The difficulty scale was attached to the memory drum above the slot in which the word appeared, and the experimenter recorded each difficulty rating the subject made. In addition, the 28 subjects in the remember condition were told that they would later be asked to recall as many of the words as they could. The 28 subjects in the story condition were told only to make their sentences part of a continuous story, which they were to make up as each word was presented. These subjects were told nothing about a later recall of the words on the list. The main list of 42 words was preceded by a practice list of 6 words. After the practice list was presented, each subject in the remember condition was given $30 \mathrm{sec}$ to write down as many of the practice words as he could. Each subject in the story condition was asked only if he had any questions. After presenting the main list, both groups were given $4 \mathrm{~min}$ to write down as many of the words from the main list as they could remember.

\section{Results}

Recall. A 2 by 4 by 3 analysis of variance was performed on the number of words recalled from each third of the list, with the factors being Learning Condition, Randomization Form, and Serial Position, respectively. Learning Condition and Randomization Form were between-subjects factors. The mean number of words recalled is shown in Figure 1. Learning Condition was significant, $F(1,48)=7.11, \mathrm{p}<.025, \mathrm{MS}_{\mathfrak{e}}=6.78$. The mean number of words recalled in the remember condition was 10.39 , and the mean number of words recalled in the story condition was 13.61. Serial Position was also significant, $\mathrm{F}(2,96)=72.87, \mathrm{p}<.001, \mathrm{MS}_{\mathrm{c}}=$ 3.13. There was a pronounced recency effect in the recall of both groups. The one significant interaction was Learning Condition by Randomization Form by Serial Position, $F(6,96)=3.03, p<.025, M_{e}=3.13$. This was probably the result of the presence of series of words in some of the lists which were particularly easy for subjects in the story condition to remember.

Difficulty. The same analysis that was performed on the recall data was also performed on the mean difficulty ratings in each third of each list. The only significant factor was Learning Condition, $F(1,48)=$ $7.06, p<.025, \mathrm{MS}_{\mathrm{e}}=1.06$. The mean difficulty rating

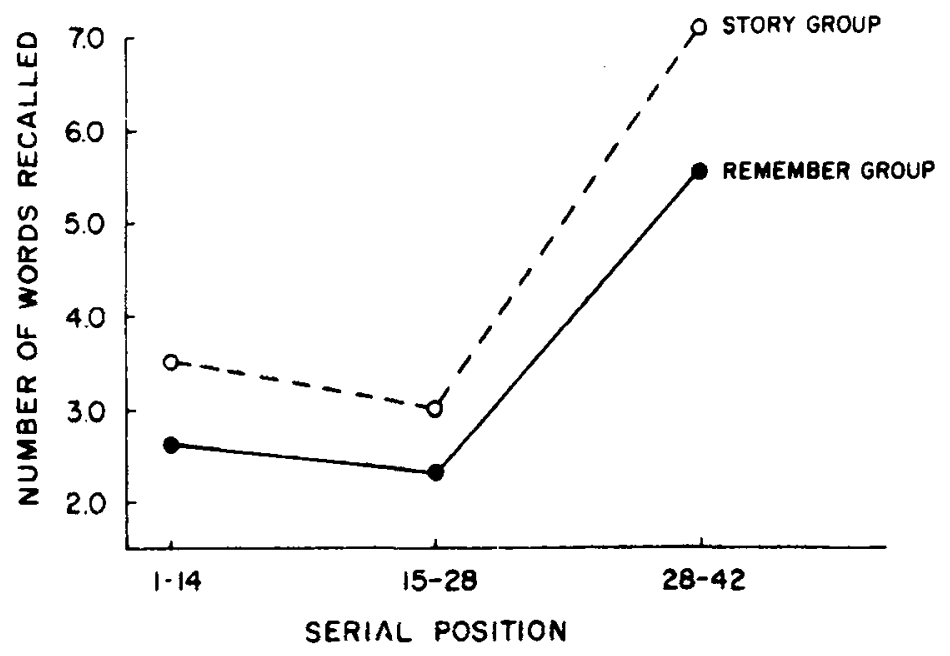

Figure 1. Mean number of words recalled from each third of the list by the remember and story groups in Experiment I. 
given by the remember group was 2.38 , while the mean difficulty rating given by the story group was 2.81 . Thus, the story group rated the words as more difficult than did the remember group.

Correlation of recall with difficulty. Hyde (1973) found that the difficulty of the semantic tasks performed on a list of words did not affect the recall of those words. However, in the present experiment, the more difficult semantic task corresponded to the better recall task. It may be that the story condition results in better recall and just happens to be the more difficult condition. In order to determine if the more difficult words within either experimental condition are better recalled or more poorly recalled, a point-biserial correlation (McNemar, 1962) was computed between the difficulty rating of each word and whether or not it was recalled. This was done for each subject separately. Each correlation was then transformed using Fisher's $z$ transformation (McNemar, 1962). The two mean correlation values were essentially zero, in agreement with Hyde (1973).

Sequential organization. Deese and Kaufman (1957) found that the order of recall of words from passages of connected discourse correlated positively with the order of presentation. In the present experiment, subjects in the story group were asked to make up a story out of the words as the words were presented. Perhaps imposition of this sequential organization on the words should result in the words being recalled in an order similar to the order of presentation. The analysis used to test this hypothesis was similar to the analysis used by Deese and Kaufman. Each subject's set of recalled words was ranked according to both presentation order and order of recall, and a Spearman rank correlation coefficient was computed for each subject. Each correlation was then transformed using Fisher's $z$ transformation, and the mean correlation for the remember group and for the story group was computed. The two mean correlations were not significantly different, but the overall mean correlation, -.36 , was significantly less than zero, $F(1,54)=19.01, p<.001$, $\mathrm{MS}_{\mathrm{e}}=.43$. For both groups, the words that were presented late in the list were recalled first. This can be seen in the pronounced recency effect shown in Figure 1 .

\section{Discussion}

As was predicted, semantic processing does not appear to be sufficient for optimal recall. Organization also seems to be necessary. Although the subjects in the remember group knew that they were going to be asked to recall the words, they did not perform as well as those subjects who did not know of the recall task, but who were organizing the words in a way that would make them more retrievable. This conclusion is in accord with Postman's (1964) contention that intent per se has no significant effect on learning, but only indicates to the subject that he should process the material in a way that is favorable to the acquisition of the material. It was hypothesized in the introduction that the subjects in the story condition are given a method of organizing the words on the list that is better than the method most subjects in the remember condition are able to use on their own. However, using this story mnemonic (Bower $\&$ Clark, 1969) seemed to require more effort on the part of the subject than did the processes used by subjects in the remember condition. This was evidenced by the larger mean difficulty rating assigned to the set of words by the story group. But, in both the remember group and in the story group, no correlation was found between the rated difficulty of the word and whether or not the word was recalled. These results agree with the results of Hyde (1973) and Walsh and Jenkins (1973), who have shown that the amount of effort expended in a task performed on a word is not in general related to the recall of that word.

The result that the correlation between the order of presentation and the order of recall was negative and the same for each group indicates that any organization connecting the story words was not strongly sequential. Many of the stories that were made up were loose elaborations of a central theme and did not have the coherence of the textual passages reported by Deese and Kaufman (1957). The words used were randomly selected and randomly ordered nouns and this may have placed a limit on the amount and type of organization that was possible. For example, the first six words of the first list were: interest, umbrella, king, bagpipe, body, truce. In addition, recall for both groups began immediately after the last word was presented. This may have encouraged the subjects to first recall the last few words presented. In Experiment II, a task interpolated between presentation and recall was used to try to reduce this recency effect.

In Experiment I different subjects were used for each condition. Till and Jenkins (1973) argue that better recall could be the result of differences in general set between the two groups. Perhaps a general learning set or a motivational set induced in the story group resulted in their processing the words to a deeper level, which in turn led to better recall of the words and also a higher difficulty rating of the words. Experiment II was designed so that each subject received both remember and story words. Also, recall of the words was followed by a recognition test that was used as an additional measure of the degree to which the words were processed (Eagle \& Leiter, 1964). Mandler (1972) indicates that organization could have a beneficial effect on recognition if the distractor words used are words not used previously in the experiment.

\section{EXPERIMENT II}

\section{Method}

Subjects. The subjects were 24 volunteers from introductory psychology courses at Ohio University who received course credit for their participation. 
Materials and apparatus. Four randomized lists of nouns were generated, each consisting of a practice list of 8 words and a main list of 40 words. The words in each list were randomly sampled from the norms of Paivio et al. (1968), with the restriction that no word was more than eight letters long.

Procedure. The subjects were tested individually using a Lafayette IBM memory drum. Each subject was randomly assigned to a list when he arrived for the experiment. The subjects were told that the purpose of the experiment was to rate the difficulty of words which were being considered for use in grade school textbooks. On two of the four randomization forms, all the odd-numbered words were preceded by an $\mathrm{X}$ and all the even-numbered words were preceded by an $O$. On the other two randomization forms, the odd-numbered words were preceded by an $O$ and the even-numbered words were preceded by an X. Each word was presented for $15 \mathrm{sec}$, and the subject was instructed to give a sentence using the word in a meaningful way and then to verbally rate the difficulty of the word using a 3-point scale of difficulty. A rating of 1 indicated that the word was easy and a 3 that it was difficult. In addition, half of the subjects were instructed to (a) try to remember the $\mathrm{X}$ words and (b) make the $\mathrm{O}$-word sentences part of a continuing story. The other half of the subjects tried to remember the $O$ words and made the $X$ words part of a continuing story.

After the eight-word practice list was presented, each subject was given $30 \mathrm{sec}$ to write down as many of the four remember words as he could. This was done to emphasize the instruction that the recall test would be for the remember words only. After the main list had been presented, each subject was given 1 min to write down any 12 new words that were not on the list that started with the letter "a." This was done to eliminate from short-term store any words from the list. Each subject was then given $1 \mathrm{~min}$ to write down as many of the remember words as he could, followed by 1 min to write down as many of the story words as he could. The subject was then given $2 \mathrm{~min}$ to write down any additional words from the list that he could remember. The remember words were requested first, so that any effects of output interference would adversely affect the recall of the story words (Roediger, 1974).

After the recall period, the subject was presented with a sheet on which were printed the $20 \mathrm{X}$ words and 20 distractors drawn from the same population of nouns. The words were in a random order. The subject was to write next to each word a $\mathrm{Y}$ or an $\mathrm{N}$, indicating whether or not the word had appeared on the list. He also indicated how confident he was of each response. A 3 indicated that he was very sure, a 2 indicated that he was fairly sure, and a 1 indicated that he was not sure. When finished with the first recognition test, the subject was given a second sheet containing the 200 words and 20 new distractors. Again the subject was to write down next to each word whether or not it had appeared on the list and how confident he was of his judgment. The subjects were told only that each sheet contained both list words and words not on the list. Two response sheets were used, so that each word on the list could be categorized as the same type of target word or as a distractor. The procedure also insured that remembes words would be tested first for recognition half the time and story words would be tested first the other half of the time.

\section{Results}

Recall. A 2 by 4 analysis of variance was performed on the number of words recalled from each quarter of the list. The factors were Learning Condition and Serial Position, respectively, and both factors were within-subjects factors. The recall means are shown in Figure 2. Learning Condition was significant, $F(1,23)=$ $44.88, \mathrm{p}<.001, \mathrm{MS}_{\mathrm{e}}=.88$. The mean number of remember words recalled was 6.04 and the mean number of story words recalled was 9.67. Serial Position was also significant, $\mathrm{F}(3,69)=9.79, \mathrm{p}<.001, \mathrm{MS}_{\mathrm{e}}=1.30$. As shown in Figure 2, both curves show a primacy and a recency effect.

Difficulty. The same analysis as was performed on the recall data was done on the mean difficulty ratings for the remember and story words in each quarter of the list. The mean difficulty rating for the remember words was 1.44 , while the mean difficulty ratings for the story words was $1.65, F(1,23)=17.46, p<.001$, $\mathrm{MS}_{\mathrm{e}}=.12$. Story words were rated more difficult than remember words.

Correlation of recall with difficulty. As in Experiment $I$, the point-biserial correlations between difficulty ratings and word recall were compared separately for the remember words and for the story words for each subject. The two mean correlation values were essentially zero.

Sequential organization. Each subject's set of recalled remember words and recalled story words was ranked according to both their order of presentation and their order of recall, and a Spearman rank correlation coefficient was computed for each set. After performing Fisher's $\mathrm{z}$ transformation on each correlation, the two mean correlations were found not to be significantly different, but the overall mean correlation, .34 , was significantly greater than zero, $F(1,23)=10.95$, $\mathrm{p}<.01, \mathrm{MS}_{\mathrm{e}}=.53$.

Recognition. Both sets of words were recognized almost perfectly. The probability of correctly recognizing either the remember or the story words was .97 after a linear correction for guessing was made. Thus, the organization instructions had no measurable effect on recognition performance.

\section{Discussion}

As in Experiment I, the remember words were not

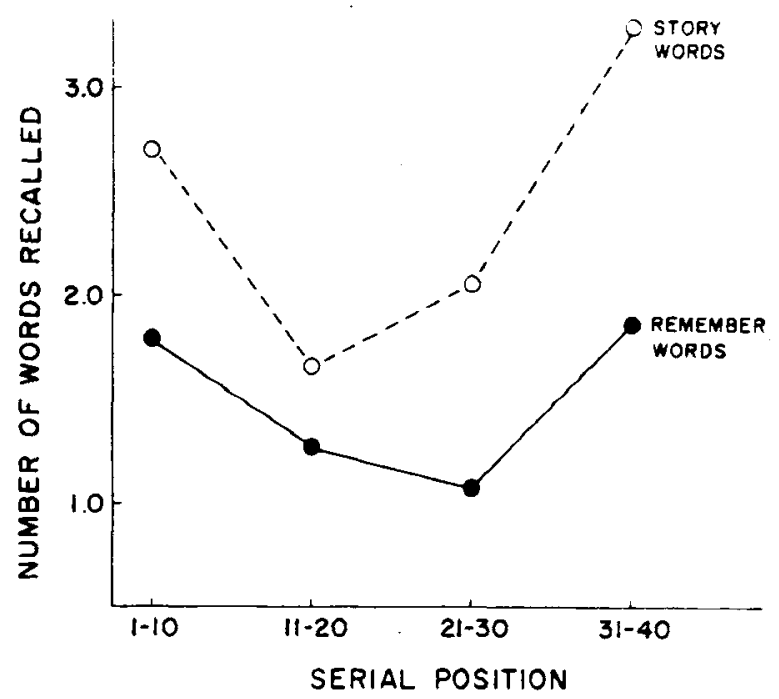

Figure 2. Mean number of remember words and story words recalled from each quarter of the list in Experiment II. 
recalled as well as the story words. This was true even though recognition of the words in each set was almost perfect. Using the terminology of Tulving and Pearlstone (1966), both sets of words were equally available, but the story words may have been more accessible because they were better organized. The result that the story words were again rated more difficult than were the remember words seems to indicate that using a story mnemonic is more difficult for the subject than merely using each word in a sentence. This seems to be true even though the subject does not know that he will be later asked to recall the story words. This, perhaps, helps explain why the story mnemonic is not naturally used by more people. If the difficulty rating was related to the depth of processing, then the words rated as more difficult should have been recalled better, which was not the case. There was no evidence for greater sequential organization in the story words when compared to the remember words. The only difference from the results of Experiment I is that both sets of words had recall orders that were positively correlated with the order of presentation. The presence of the interpolated task led to fewer words immediately recalled from shortterm store.

Mandler (1968, p. 114), in discussing the formation of organization systems in a free recall task, suggested that the experimentally formed sets are transient and would not survive the experimental situation more than a few minutes or hours. In Experiment III, the effects of semantic processing and organization on retention were determined by testing the subjects for recall and recognition $24 \mathrm{~h}$ after the word list had been presented.

\section{EXPERIMENT III}

\section{Method}

Subjects. The subjects were 32 volunteers from introductory psychology courses at Ohio University. They received course credit for their participation.

Procedure. The materials and procedures used were exactly the same as those used in Experiment I, except that immediately after the list of remember and story words was presented, each subject was told not to think about the words on the list and was dismissed. Before the experiment began, it had been arranged with each subject only that he was to return $24 \mathrm{~h}$ later for a second session.

\section{Results}

Recall. A 2 by 4 analysis of variance was performed on the number of words recalled from each quarter of the list, with the factors being Learning Condition and Serial Position, respectively. Both factors were withinsubjects factors. The recall means are shown in Figure 3. Learning Condition was significant, $F(1,31)=20.99$, $\mathrm{p}<.001, \mathrm{MS}_{\mathrm{e}}=.79$, where the mean number of remember words recalled was 3.72 and the mean number of story words recalled was 5.75 . Serial Position was also significant, $\mathrm{F}(3,93)=3.15, \mathrm{p}<.05, \mathrm{MS}_{\mathrm{e}}=1.10$. Although the curves appear to diverge, the Learning

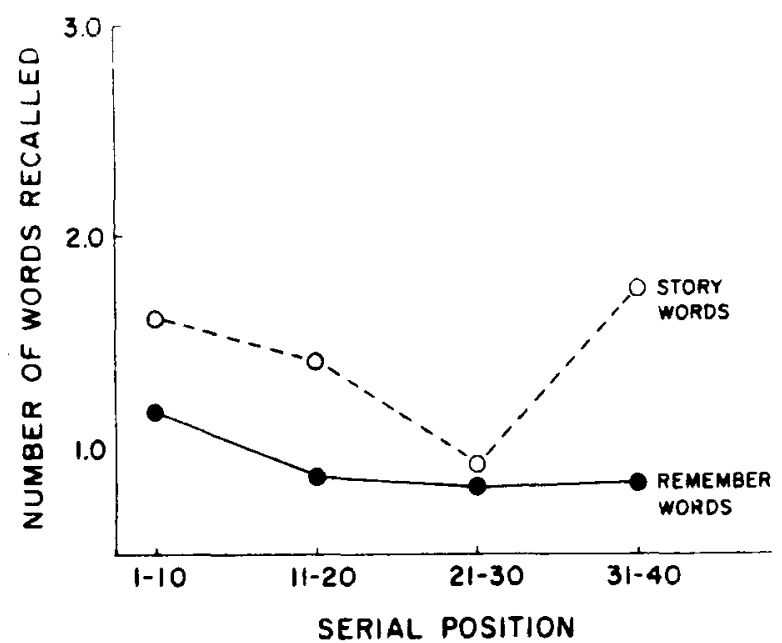

Figure 3. Mean number of remember words and story words recalled from each quarter of the list in Experiment III.

Condition by Serial Position interaction was not significant, $F(3,93)=2.16, p>.05$.

Difficulty. The rated difficulty for the remember words was again significantly lower than the rated difficulty of the story words, $F(1,31)=49.21, \mathrm{p}<.001$, $\mathrm{MS}_{\mathrm{e}}=.22$, with the means being 1.44 and 1.86 , respectively.

Correlation of recall with difficulty. The pointbiserial correlations between difficulty rating and recall were computed separately for each subject for both the remember and the story words. There was no significant difference between the remember-word and the storyword correlations. The mean correlations were again essentially zero.

Sequential organization. The mean correlations between order of presentation and order of recall were again not significantly different, but the overall mean correlation, .39 , was significantly greater than zero, $\mathrm{F}(1,31)=8.19, \mathrm{p}<.01, \mathrm{MS}_{\mathrm{e}}=1.33$.

Recognition. A treatment by subjects analysis of variance was performed on the pairs of recognition scores from each subject after they had been linearly corrected for guessing using the individual subject's guessing rates. The mean probability of recognition was identical, .91, for both the remember and for the story words. A signal detection analysis (Banks, 1970) yielded $d^{\prime} s$ of 2.57 and 2.51 for the remember words and the story words, respectively. These d's were not significantly different.

\section{Discussion}

The results of Experiment III are consistent with those of Experiments I and II. The story words were recalled better than were the remember words even after a 24 -h retention interval. Comparing these results to those of Experiment II, approximately $60 \%$ of the number of words recalled after a 1-min delay were recalled after a $24-\mathrm{h}$ delay. Thus, the difference at immediate recall persists for $24 \mathrm{~h}$. The story words were again rated as being more difficult than were the 
remember words, even though each word was used as a story word and a remember word an equal number of times. It appears that each subject's rating of the difficulty of the words was influenced by the difficulty the subject experienced in forming a sentence for the word. It probably was more difficult to form a meaningful sentence that was part of a continuing story than to merely form a meaningful sentence. The results with respect to sequential organization were almost identical to those of Experiment II. The recall order of both the remember words and the story words was positively correlated with the presentation order.

Experiments II and III showed that the type of organization instructions used in these experiments, the story mnemonic, had an effect on recall, but had no effect on recognition. The result that recognition was above .90 even after $24 \mathrm{~h}$ indicates that all the words on each set were extensively processed.

\section{GENERAL DISCUSSION}

The hypothesis stated in the introduction has been generally supported by the results of the three experiments. The story words were always recalled significantly better than were the remember words. The recognition rates for both types of words were very high and almost identical, which indicates that both types of words were extensively processed. The result that the story words were always rated as more difficult than were the remember words may appear to support the hypothesis that the story words were more deeply processed. However, if this was true, then the words rated as more difficult within the set of remember words or within the set of story words should have been recalled better than the words rated as less difficult. This was never the case. In all three experiments, the correlation between the recall of a word and its rated difficulty was zero. An alternative explanation is that the story words were rated as more difficult because creating an organizational structure for the story words was a difficult task. In all three experiments, the recalled remember words and the recalled story words had the same amount of sequential organization when order of recall was compared to order of presentation. This result does not support the organizational hypothesis. However, as was mentioned above, the stories that the subjects made up were often only loose elaborations of a central theme with little apparent sequential structure.

It seems that organization of the randomly selected words using a semantic scheme such as the story mnemonic is dependent on the words first being semantically processed, that is, comprehended. However, the degree of organization that takes place along with the semantic processing may depend on additional activity of a different kind. As Miller, Galanter, and Pribram (1960) point out, the subject must have a plan for organizing the words so that he can subsequently retrieve them during the recall task (see also Bower, 1970, 1972; Mandler, 1968; Slamecka, 1968). A retrieval scheme or plan based on the organizing activities of the subject must be present both during the presentation of the items and during recall. Many of the mnemonic procedures which use visual imagery and verbal elaboration such as the peg-word system (Miller et al., 1960), the method of loci (Crovitz, 1970), and the use of stories (Bower \& Clark, 1969) allow the subject to create an event which can be remembered much like a real event. Hence, the subject is able to remember new information better if he can relate the new information to a structure or form that is familiar and is already stored in memory.

The relation between semantic processing and organization proposed here may provide a useful way to synthesize two lines of research that previously have been dealt with independently.

\section{REFERENCES}

Banks. W. P. Signal detection theory and human memory. Psychological Bulletin, 1970, 74, 81-99.

Bower, G. H. Organizational factors in memory. Cognitive Psychology, 1970, 1. 18-46.

BowER, G. H. A selective review of organizational factors in memory. In E. Tulving \& W. Donaldson (Eds.), Organization of Memory. New York: Academic Press, 1972.

Bower. G. H., \& Clark. M. C. Narrative stories as mediators for serial learning. Psychonomic Science, 1969, 14, 181-182.

CraIK, F. I. M. A "levels of analysis" view of memory. In P. Pliner, L. Krames, \& T. Alloway (Eds.), Communication and affect: Language and thought. New York: Academic Press, 1973.

Craik. F. I. M., \& Lockhart, R. S. Levels of processing: A framework for memory research. Journal of Verbal Learning and Verbal Behavior, 1972, 11,671-684.

Crovitz, H. F. Galton's walk. New York: Harper \& Row, 1970.

Defse, J., \& Kaufman. R. A. Serial effects in recall of unorganized and sequentially organized verbal material. Journal of Experimental Psychology. 1957, 54, 180-187.

EAGLE, M., \& LEITER. E. Recall and recognition in intentional and incidental learning. Journal of Experimental Psychology, 1964, 68, 58-63.

HYDE, T. S. Differential effects of effort and type of orienting task on recall and organization of highly associated words Journal of Experimental Psychology, 1973, 97, 111-113.

HydE, T. S., \& JEN KINS, J. J. Differential effects of incidental tasks on the organization of recall of a list of highly associated words. Journal of Experimental Psychology, 1969, 82, 472-481.

JENKINS, J. J. Remember that old theory of memory? Well, forget it! American Psychologist, 1974, 29, 785-795.

MaNdler, G. Organization and memory. In K. W. Spence \& 3. T. Spence (Eds.). The psychology of leaming and motivation (Vol. 1). New York: Academic Press, 1967.

Mandler, G. Association and organization: Facts, fancies, and theories. In T. R. Dixon \& D. L. Horton (Eds.), Verbal behavior and general behavior theory. Englewood Cliffs, N.J: Prentice-Hall, 1968

Mandler, G. Words, lists, and categories: An experimental view of organized memory. In J. L. Cowan (Ed.). Studies in thought and language. Tucson, Ariz: University of Arizona Press, 1970.

Mandler, G. Organization and recognition. In E. Tulving \& W. Donaldson (Eds.). Organization of memory. New York: Academic Press, 1972. 
McNemar, Q, Psychological statistics (3rd ed.). New York: Willey, 1962.

Miller, G. A., Galanter, E., \& Pribram, K. H. Plans and the structure of behavior. New York: Holt, Rinehart and Winston, 1960.

Paivio, A., Yuille, J. C.. \& Madigan, S. A. Concreteness, imagety, and meaningfulness values for 925 nouns. Journal of Experimental Psychology. Monograph Supplement. 1968 , 76(1, Pt. 2).

Postman, L. Short-term memory and incidental learning. In A. W. Melton (Ed.), Categories of human learning. New York: Academic Press, 1964.

Roediger, H. L. Inhibiting effects of recall. Memory \& Cognition, 1974, 2, 261-269.

Slamecka, N. J. An examination of trace storage in free recall. Journal of Experimental Psychology, 1968, 76, 504-513.

TILL, R. E., \& JENXINS, J. J. The effects of cued orienting tasks on the free recall of words. Journal of Verbal Leaming and Verbal Behavior, 1973, 12, 489-498.
Tulving, E. Subjective organization in free recall of "unrelated words." Psychological Review, 1962, 69, 344-354.

Tulving, E. Theoretical issues in free recall. In T. R. Dixon \& D. L. Horton (Eds.), Verbal behavior and general behavior theory. Englewood Cliffs, N.J: Prentice-Hall, 1968.

Tulving, E. Episodic and semantic memory. In E. Tulving \& W. Donaloison (Eds.), Organization of memory. New York: Academic Press, 1972.

Tulving, E., \& Pearlstone, Z. Availability versus accessibility of information in memory for words. Journal of Verbal Learning and Verbal Behavior, 1966, 5, 381-391.

WALSH, D. A., \& JENKINS, J. J. Effects of orienting tasks on free recall in incidental learning: "Difficulty," "effort," and "process" explanations. Joumal of Verbal Learning and Verbal Behavior, 1973, 12, 481-488.

(Received for publication July 14,1975 ; revision accepted November $5,1975$. 